\title{
Determination of $\mathrm{Ag}$ and $\mathrm{Cd}$ in Soil and Sediment Samples by Graphite Furnace Atomic Absorption Spectrometry (GFAAS)
}

\author{
Manik C. Saha*, Rashmoni Baskey, and Sudipta Lahiri \\ Geological Survey of India, Central Headquarter, Chemical Division, \\ 15 A \& B Kyd Street, Kolkata-700 016, India
}

\section{INTRODUCTION}

Silver (Ag) occurs in nature as sulphides, tellurides, arsenides, antimonides, and halides. It also occurs as native state and is associated with native gold and copper. The only oxygen compound of Ag known to occur in nature is argentojarosite, a sulphate of silver and iron. The crustal abundance of silver is $0.070 \mathrm{ppm}$ and of cadmium it is $0.1 \mathrm{ppm}$. Cadmium (Cd) is a relatively rare metal and found in association with zinc (Zn) (1). It occurs usually as green ockite associated with sphalerite. The Geological Survey of India has taken up the National Geochemical Mapping (NGCM) program and 68 elements are to be determined in soil and sediments at their crustal abundance level or below. The 68 elements are divided into 10 different packages, i.e., from Package A to Package J. The elements Ag and Cd come under Package $\mathrm{F}$ and the required detection limits were set as 20 and $100 \mathrm{ppb}$, respectively. These elements are very useful in geochemical exploration.

Elemental analysis by graphite furnace atomic absorption spectrometry (GFAAS) is normally carried out in the solution phase (2). Geological samples, e.g., soils, sediments, rocks, ores, minerals, etc., are usually brought into solution by mineral acid digestion. Dissolution of geological samples to bring $\mathrm{Ag}$ and $\mathrm{Cd}$ in solution is an important part of the analysis. Matrix and background absorbance

\footnotetext{
* Corresponding autbor.

E-mail: manikchandra.saba@yaboo.com
}

\begin{abstract}
${ }^{\circ \cdot}$
An extensive study has been made for the determination of silver $(\mathrm{Ag})$ and cadmium $(\mathrm{Cd})$ in soil and sediment samples using different decomposition procedures. A simple and rapid method has been developed for the accurate determination of $\mathrm{Ag}$ and $\mathrm{Cd}$ at ppb levels by graphite furnace atomic absorption spectrometry (GFAAS). In the present study, -200 mesh size samples were digested in a $100-\mathrm{mL}$ glass beaker using 1:1 $\mathrm{HNO}_{3}$ for measurement of $\mathrm{Ag}$ and Cd by GFAAS. A bulk calibration standard of $20 \mathrm{ppb}$ of $\mathrm{Ag}$ and $10 \mathrm{ppb}$ of Cd was used for the measurement of silver and cadmium, respectively. The method was proposed for the determination of $\mathrm{Ag}$ and $\mathrm{Cd}$ in soil and sediment samples collected according to the guidelines of the National Geochemical Mapping (NGCM) program and is being followed by the Geological Survey of India with an objective for Geochemical Mapping. The precision of the proposed method was investigated by analyzing 10 soil and sediment samples, and the estimated value of the RSD (\%) was found to be $<10 \%$. The efficiency of the method was also compared by analyzing 10 international soil and sediment reference samples. Very good agreement and excellent precision were observed for the certified values. The limit of quantitation $(10 \sigma)$ achieved for $\mathrm{Ag}$ was $5.0 \mathrm{ng} / \mathrm{g}$ and for $\mathrm{Cd}$ it was $2.0 \mathrm{ng} / \mathrm{g}$, with a recovery of 95-103\%
\end{abstract}

- The abstract of this article was published in the 43rd Chemist Convention conducted by the Indian Chemical Society. play a vital role for the estimation of elements by GFAAS at such a low level of concentration. Viets et al. (3) determined these elements by flame atomic absorption spectrometry (FAAS) using alkaline fusion, followed by hydrochloric acid dissolution and pre-concentration in an organic solvent resulting in a detection limit of $100 \mathrm{ppb}$. Zongshou Yu et al. (4) reported different digestion techniques such as $\mathrm{HF} / \mathrm{HClO}_{4}, \mathrm{HF} / \mathrm{HNO}_{3}$, and $\mathrm{HF} / \mathrm{H}_{2} \mathrm{SO}_{4}$ to dissolve geological samples for trace element determination. Silver and cadmium were also estimated in geological samples with the help of FAAS and GFAAS by several authors using different acid and fusion mixtures (3, 5-8). There are some complete dissolution and some partial decomposition techniques. But an accurate, precise, simple, and rapid method is required to fulfill the requirement as per the National Geochemical Mapping (NGCM) program.

In this paper, a simple and rapid dissolution procedure has been developed for the determination of $\mathrm{Ag}$ and $\mathrm{Cd}$ in geological samples collected according to the guidelines of the NGCM program. The samples were pulverized to -200 mesh sizes to reduce the probability of leaving the silver trapped in the silicate phase. The proposed method consists of two parts: dissolution and GFAAS measurement.

For geochemical mapping, the total concentration of the elements is required. These data have a multipurpose use, e.g., for mineral exploration and environmental investigative study of basic geology (9). Nitric acid digestion has been most commonly used in exploration 
geochemistry for many years, but it does not always provide a total extraction as reported by Chao and Sanzolone (10). Balaram et al. (11) studied aqua regia digestion and extraction for some base metals resulting in 95-99\% extraction. Saha et al. (5) reported a comparative study using a different dissolution procedure for the measurement of copper, lead, zinc, nickel, cobalt, silver, and cadmium and concluded that $\mathrm{HF}-\mathrm{HClO}_{4}-\mathrm{HNO}_{3}$ digestion is most suitable for the complete extraction of the metals. The present authors observed that complete extraction of $\mathrm{Ag}$ and $\mathrm{Cd}$ from soil and sediment samples is possible with $1: 1 \mathrm{HNO}_{3}$. The dilution factor is also very important for low level determination of the elements in geological samples. Flame AAS has been widely used for the trace element determination in geochemical samples (12). However, the detection limits required in NGCM samples for Ag and Cd are very low, and FAAS has not been able to achieve such low detection limits even though some authors have reported such detection limits for one or two elements, e.g., lithium and zinc (13).

Nowadays, GFAAS, inductively coupled plasma atomic emission spectrometry (ICP-AES), and inductively coupled plasma mass spectrometry (ICP-MS) are the most commonly used techniques for the determination of trace amounts of Cd and Ag (14-17). GFAAS is simple, sensitive, and cost-effective in comparison to ICP-AES and ICP-MS, but it is a great challenge to achieve the very low detection limits required for $\mathrm{Ag}$ and $\mathrm{Cd}$ in geological samples. In most cases, detection limits at the ppb level are achieved only using pre-concentration methods such as ion exchange separation, solvent extraction, etc. Sometimes it is required to digest more samples to reach detection limits at the ppb level, but interferences from high concentrations of other elements provide erroneous results. The present dissolution technique overcomes almost all possibilities of error. The limit of quantitation ( $10 \sigma)$ achieved for the estimation of $\mathrm{Ag}$ and $\mathrm{Cd}$ is much less than the crustal abundance level, which is also the required detection level for the NGCM program. The validity of the method was checked with 10 certified reference materials (CRMs).

\section{EXPERIMENTAL}

\section{Instrumentation}

All analyses were performed using a Varian 220 FS atomic absorption spectrophotometer (Varian, Palo Alto, CA, USA). The analytical parameters used for the determination of $\mathrm{Ag}$ and $\mathrm{Cd}$ by GFAAS are listed in Table I. The temperature profile for measurement of $\mathrm{Ag}$ and $\mathrm{Cd}$ is depicted in Tables II and III, respectively.

TABLE I

Instrumental Parameters for GFAAS Measurement of Ag and Cd

\begin{tabular}{|c|c|c|c|c|c|}
\hline & Ag & $\mathrm{Cd}$ & & Ag & $\mathrm{Cd}$ \\
\hline $\begin{array}{l}\text { Sampling } \\
\text { Mode }\end{array}$ & $\begin{array}{l}\text { Auto } \\
\text { Mix }\end{array}$ & $\begin{array}{l}\text { Auto } \\
\text { Mix }\end{array}$ & $\begin{array}{l}\text { Calibration } \\
\text { Mode }\end{array}$ & $\begin{array}{l}\text { Concen } \\
\text { tration }\end{array}$ & $\begin{array}{l}\text { Concen- } \\
\text { tration }\end{array}$ \\
\hline $\begin{array}{l}\text { Measurement } \\
\text { Mode }\end{array}$ & $\begin{array}{l}\text { Peak } \\
\text { Height }\end{array}$ & $\begin{array}{l}\text { Peak } \\
\text { Height }\end{array}$ & $\begin{array}{l}\text { Wave- } \\
\text { length }\end{array}$ & $328.1 \mathrm{~nm}$ & $228.8 \mathrm{~nm}$ \\
\hline Slit Width & $0.5 \mathrm{~nm}$ & $0.5 \mathrm{~nm}$ & $\begin{array}{l}\text { Lamp } \\
\text { Current* }\end{array}$ & $4.0 \mathrm{~mA}$ & $4.0 \mathrm{~mA}$ \\
\hline $\begin{array}{l}\text { Background } \\
\text { Corrector }\end{array}$ & $\mathrm{ON}$ & $\mathrm{ON}$ & $\begin{array}{l}\text { Conc. } \\
\text { Decimal } \\
\text { Places }\end{array}$ & 2 & 2 \\
\hline $\begin{array}{l}\text { Sample } \\
\text { Volume }\end{array}$ & $20 \mu \mathrm{L}$ & $10 \mu \mathrm{L}$ & $\begin{array}{l}\text { Total } \\
\text { Volume }\end{array}$ & $25 \mu \mathrm{L}$ & $15 \mu \mathrm{L}$ \\
\hline Bulk Conc. & $20 \mu \mathrm{g} / \mathrm{L}$ & $10 \mu \mathrm{g} / \mathrm{L}$ & $\begin{array}{l}\text { Calibration } \\
\text { Standards } \\
(\mu \mathrm{g} / \mathrm{L})\end{array}$ & $2,10,20$ & $2,5,10$ \\
\hline
\end{tabular}

* Parameter may change depending on the model of the instrument.

TABLE-II

Temperature Profile for Ag Measurement

\begin{tabular}{crrrlcc}
\hline Step & $\begin{array}{c}\text { Temp. } \\
\left({ }^{\circ} \mathrm{C}\right)\end{array}$ & $\begin{array}{c}\text { Time } \\
(\mathrm{sec})\end{array}$ & $\begin{array}{c}\text { Flow } \\
(\mathrm{L} / \mathrm{min})\end{array}$ & $\begin{array}{c}\text { Gas } \\
\text { Type }\end{array}$ & Read & $\begin{array}{l}\text { Signal } \\
\text { Storage }\end{array}$ \\
\hline 1 & 85 & 5.0 & 3.0 & Normal & No & No \\
2 & 95 & 30.0 & 3.0 & Normal & No & No \\
3 & 120 & 10.0 & 3.0 & Normal & No & No \\
4 & 700 & 25.0 & 3.0 & Normal & No & No \\
5 & 700 & 2.9 & 3.0 & Normal & No & No \\
6 & 750 & 2.9 & 0 & Normal & No & Yes \\
7 & 2100 & 0.8 & 0 & Normal & Yes & Yes \\
8 & 2100 & 2.0 & 0 & Normal & Yes & Yes \\
9 & 2150 & 2.0 & 3.0 & Normal & No & Yes \\
\hline
\end{tabular}




\section{Reagents and Standard Solutions}

All reagents used were of analytical reagent (AR) grade. Distilled 1:1 $\mathrm{HNO}_{3}$ was preferred for the procedure.

Silver and cadmium standards were prepared from silver nitrate and cadmium nitrate (obtained from Johnson and Mathey Chemical Ltd., Royston, U.K).

Stock solutions were made of 100 ppm Ag and 100 ppm Cd solution.

100 ppm Ag: $0.17 \mathrm{~g}$ of $\mathrm{AgNO}_{3}$ (SpecPure ${ }^{\circledR}$ ) was dissolved in $25 \mathrm{~mL}$ $5 \% \mathrm{HNO}_{3}$, and the volume was made up to $1000 \mathrm{~mL}$, maintaining $5 \% \mathrm{HNO}_{3}$ concentration.

100 ppm Cd: $0.236 \mathrm{~g}$ of $\mathrm{Cd}\left(\mathrm{NO}_{3}\right)_{2}$ was dissolved in $25 \mathrm{~mL}$ of $5 \% \mathrm{HNO}_{3}$, and the volume was made up to $1000 \mathrm{~mL}$, maintaining $5 \% \mathrm{HNO}_{3}$ concentration.

Sub-standard solutions: 1.0 and $0.5 \mathrm{ppm}$ solutions of $\mathrm{Ag}$ and $\mathrm{Cd}$, respectively, were prepared by successive serial dilution of the 100 ppm stock solution.

Mixed calibration standard (bulk): $20 \mathrm{ppb}$ and $10 \mathrm{ppb}$ mixed standard solutions of $\mathrm{Ag}$ and $\mathrm{Cd}$ were prepared with $5 \% \mathrm{HNO}_{3}$ by dilution of the $1.0 \mathrm{ppm}$ and $0.5 \mathrm{ppm}$ Ag and Cd solutions, respectively.
High purity Milli-Q ${ }^{\circledR}$ water $(18 \mathrm{M} \Omega \cdot \mathrm{cm})$ was used for all of the sample and standard preparation procedures. All glassware and digestion vessels were acid-washed and rinsed with Milli-Q water.

\section{Certified Reference Materials (CRMs)}

For this study, the authors have selected 10 CRMs obtained from the China National Analysis Centre for Iron and Steel, Beijing, P.R. China. There are five certified soil reference samples (GSS-1, GSS-2, GSS-3, GSS-5, and GSS-8) and five certified sediment reference samples (GSD-3, GSD-4, GSD-5, GSD-6, and GSD-10).

\section{Dissolution Procedure for the Geological Samples and CRMs}

A 2.0-g sample (-200 mesh) was taken into a 250-mL glass beaker, and $80 \mathrm{~mL}(1: 1) \mathrm{HNO}_{3}$ (AR) was added. The beaker was covered with a glass lid, placed on a hot plate, and boiled gently for 2.0-2.5 hours. The lid was removed and the solution evaporated slowly to a pasty mass. Then, $10 \mathrm{~mL}$ of $5 \%$ $\mathrm{HNO}_{3}$ was added, warmed for 5 minutes, removed from the hot plate, and cooled. The contents were transferred to glass-stoppered graduated test tubes, and the volume was made up to $20 \mathrm{~mL}$ with demineralized water. The

TABLE III

Temperature Profile for Cd Measurement

\begin{tabular}{ccccccc}
\hline Step & $\begin{array}{c}\text { Temp. } \\
\left({ }^{\circ} \mathrm{C}\right)\end{array}$ & $\begin{array}{c}\text { Time } \\
(\mathrm{sec})\end{array}$ & $\begin{array}{c}\text { Flow } \\
(\mathrm{L} / \mathrm{min})\end{array}$ & $\begin{array}{c}\text { Gas } \\
\text { Type }\end{array}$ & Read & $\begin{array}{c}\text { Signal } \\
\text { Storage }\end{array}$ \\
\hline 1 & 85 & 5.0 & 3.0 & Normal & No & No \\
2 & 95 & 30.0 & 3.0 & Normal & No & No \\
3 & 120 & 10.0 & 3.0 & Normal & No & No \\
4 & 300 & 30.0 & 3.0 & Normal & No & No \\
5 & 300 & 2.5 & 3.0 & Normal & No & No \\
6 & 400 & 2.5 & 3.0 & Normal & No & Yes \\
7 & 2000 & 0.8 & 0 & Normal & Yes & Yes \\
8 & 2000 & 2.0 & 0 & Normal & Yes & Yes \\
9 & 2100 & 2.0 & 3.0 & Normal & No & Yes \\
\hline
\end{tabular}


TABLE IV

Results of Ag and Cd Determination in CRMs by GFAAS

\begin{tabular}{|c|c|c|c|c|c|c|}
\hline \multirow[t]{2}{*}{ Sample } & \multicolumn{3}{|c|}{$\mathrm{Ag}(\mathrm{ng} / \mathrm{g})$} & \multicolumn{3}{|l|}{ Cd (ng/g) } \\
\hline & Observed & $\begin{array}{c}\text { Determined } \\
\text { mean } \pm \text { SD }\end{array}$ & Certified & Observed & $\begin{array}{c}\text { Determined } \\
\text { mean } \pm \text { SD }\end{array}$ & Certified \\
\hline GSS-1 & $366,381,400,389,406,398$ & $390 \pm 14.68$ & $350 \pm 70$ & $4375,4500,4213,4555,4183,4424$ & $4375 \pm 150.69$ & $4300 \pm 600$ \\
\hline GSS-2 & $53,59,52,56,57,47$ & $57 \pm 4.28$ & $54 \pm 10$ & $71,78,76,82,73,64$ & $74 \pm 6.22$ & $71 \pm 22$ \\
\hline GSS-3 & $87,93,86,83,81,80$ & $85 \pm 4.77$ & $91 \pm 11$ & $49,47,54,46,53,57$ & $51 \pm 4.33$ & $59 \pm 20$ \\
\hline GSS-5 & $\begin{array}{l}4200,4486,4314,4050 \\
4005,3965\end{array}$ & $\begin{array}{l}4170 \pm \\
202.55\end{array}$ & $\begin{array}{l}4400 \pm \\
600\end{array}$ & $460,449,435,443,403,390$ & $430 \pm 27.51$ & $450 \pm 90$ \\
\hline GSS-8 & $50,46,48,56,59,53$ & $52 \pm 4.94$ & $60 \pm 14$ & $122,130,112,103,109,120$ & $116 \pm 9.82$ & $130 \pm 50$ \\
\hline GSD-3 & $570,560,588,555,612,565$ & $575 \pm 21.39$ & $590 \pm 70$ & $97,95,92,87,83,86$ & $90 \pm 5.51$ & $100 \pm 20$ \\
\hline GSD-4 & $90,98,103,100,96,89$ & $96 \pm 5.55$ & $84 \pm 26$ & $177,194,186,173,165,167$ & $178 \pm 11.22$ & $190 \pm 30$ \\
\hline GSD-5 & $372,350,395,370,365,380$ & $372 \pm 15.03$ & $360 \pm 40$ & $820,840,828,808,780,784$ & $810 \pm 24.10$ & $820 \pm 70$ \\
\hline GSD-6 & $355,378,375,336,341,346$ & $355 \pm 17.70$ & $360 \pm 40$ & $409,435,402,416,390,420$ & $412 \pm 15.50$ & $430 \pm 30$ \\
\hline GSD-10 & $261,252,240,287,280,246$ & $261 \pm 18.89$ & $270 \pm 30$ & $1174,1067,1140,1096,1125,1130$ & $1122 \pm 36.88$ & $1120 \pm 120$ \\
\hline
\end{tabular}

$\mathrm{SD}=$ standard deviation of six determinations.

TABLE V

Results of Ag and Cd Determination of 10 Soil and Sediment Samples by GFAAS

\begin{tabular}{|c|c|c|c|c|}
\hline \multicolumn{2}{|c|}{ Sample ID } & \multirow[t]{2}{*}{ Sample Type } & \multicolumn{2}{|c|}{$\begin{array}{c}{ }^{\mathrm{a}} \text { Determined mean } \pm \mathrm{SD} \\
{ }^{\mathrm{b}} \mathrm{RSD}(\%)\end{array}$} \\
\hline & & & Ag (ng/g) & Cd (ng/g) \\
\hline 1. & $14935-1$ & Soil & $\begin{array}{c}21 \pm 1.34 \\
(6.38)\end{array}$ & $\begin{array}{c}59 \pm 2.13 \\
(3.61)\end{array}$ \\
\hline 2. & $14935-10$ & Soil & $\begin{array}{c}26 \pm 1.55 \\
(5.96)\end{array}$ & $\begin{array}{c}63 \pm 1.98 \\
(3.14)\end{array}$ \\
\hline 3. & $14935-21$ & Soil & $\begin{array}{c}44 \pm 1.87 \\
(4.25)\end{array}$ & $\begin{array}{c}125 \pm 1.87 \\
(1.49)\end{array}$ \\
\hline 4. & $14935-31$ & Soil & $\begin{array}{c}20 \pm 1.42 \\
(7.10)\end{array}$ & $\begin{array}{c}50 \pm 1.74 \\
(3.48)\end{array}$ \\
\hline 5. & $14935-41$ & Soil & $\begin{array}{c}5 \pm 0.46 \\
(9.20)\end{array}$ & $\begin{array}{c}9 \pm 0.43 \\
(4.78)\end{array}$ \\
\hline 6. & $14849-1$ & Stream Sediment & $\begin{array}{c}24 \pm 1.43 \\
(5.96)\end{array}$ & $\begin{array}{c}41 \pm 1.21 \\
(2.95)\end{array}$ \\
\hline 7. & $14849-4$ & Stream Sediment & $\begin{array}{c}33 \pm 1.63 \\
(4.94)\end{array}$ & $\begin{array}{c}49 \pm 1.33 \\
(2.71)\end{array}$ \\
\hline 8. & $14849-11$ & Stream Sediment & $\begin{array}{c}27 \pm 1.59 \\
(5.89)\end{array}$ & $\begin{array}{c}46 \pm 1.56 \\
(3.39)\end{array}$ \\
\hline 9. & 14849-18 & Stream Sediment & $\begin{array}{c}23 \pm 1.26 \\
(5.48)\end{array}$ & $\begin{array}{c}42 \pm 1.37 \\
(3.26)\end{array}$ \\
\hline 10. & $14849-19$ & Stream Sediment & $\begin{array}{c}11 \pm 0.78 \\
(7.09)\end{array}$ & $\begin{array}{c}27 \pm 1.19 \\
(4.41)\end{array}$ \\
\hline
\end{tabular}

\footnotetext{
${ }^{a}$ Mean of six determinations.
}

b $\%$ RSD = relative standard deviation values listed in parentheses.. in the samples, thereby accounting for the dilution factor used. The standard calibration curves obtained for the measurement of $\mathrm{Ag}$ and $\mathrm{Cd}$ are shown in Figures 1 and 2 . The absorbance value of a 10-ppb Ag solution was 0.1974, whereas for a 4-ppb Cd solution it was 0.2253 . The characteristic concentration for $\mathrm{Ag}$ and $\mathrm{Cd}$ was 0.222 $\mathrm{ng} / \mathrm{mL}$ and $0.0781 \mathrm{ng} / \mathrm{mL}$, respectively. Thus, a solution containing $0.222 \mathrm{ng} / \mathrm{mL} \mathrm{Ag}$ and $0.0781 \mathrm{ng} / \mathrm{mL}$ Cd will give $1 \%$ absorption. The LOQ $(10 \sigma)$ observed for the quantification of Ag was $5 \mathrm{ng} / \mathrm{g}$ and for Cd $2 \mathrm{ng} / \mathrm{g}$, which is below the crustal abundance level; the RSD was $<10 \%$. These results confirm that this methodology may be used very effectively for the determination of $\mathrm{Ag}$ and $\mathrm{Cd}$ in soil and sediment samples for geochemical exploration work.

\section{CONCLUSION}

The proposed method is very simple and rapid in comparison to other dissolution techniques followed by preconcentration, it uses 


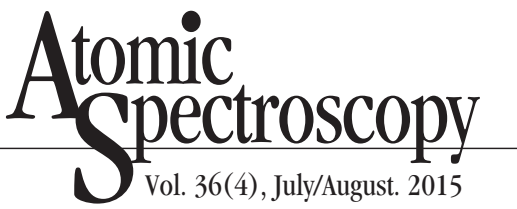

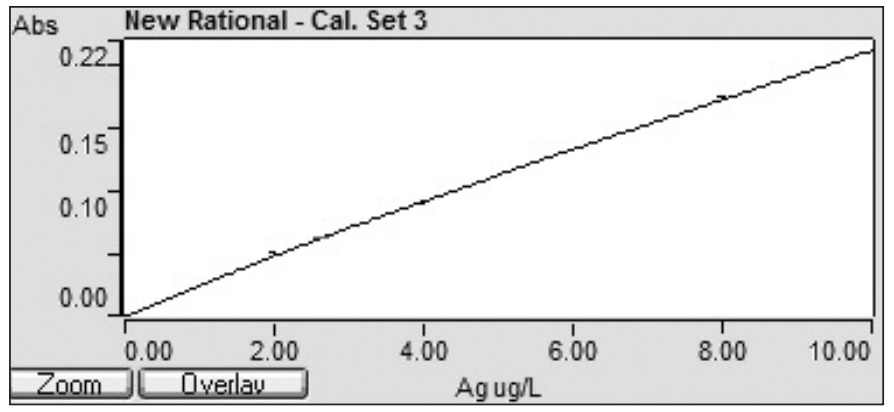

Fig. 1: Calibration Curve of Silver by GF-AAS.

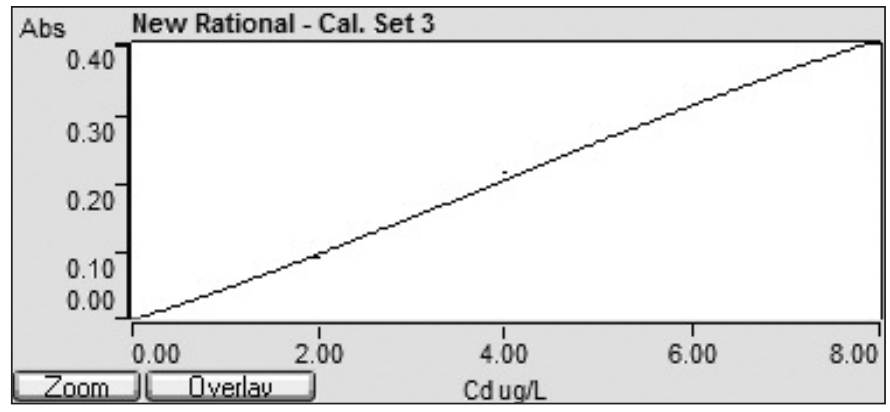

Fig. 2: Calibration Curve of Cadmium by GF-AAS. a single acid decomposition procedure, and allows complete extraction of $\mathrm{Ag}$ and $\mathrm{Cd}$. The most striking advantages of the nitric acid decomposition method are simplicity, smaller background value, and direct injection of the aqueous solution into the graphite tube with the auto-injection procedure. The method is less hazardous in comparison to the aqua regia and $\mathrm{HF}-\mathrm{HClO}_{4}$ dissolution processes which produce harmful chlorine and hydrogen fluoride gases. There is no probability of loss of the analyte element during evaporation using the proposed dissolution procedure since no volatile chlorides are formed, which is a common phenomenon in the case of aqua regia digestion methods. The crustal abundance of $\mathrm{Ag}$ is $70 \mathrm{ppb}$ and of $\mathrm{Cd}$ it is $100 \mathrm{ppb}$. The limit of quantification achieved by the proposed method is much below the crustal abundance for these elements. Due to its simplicity, rapid estimation, low cost, and achievement of a much lower detection limit, this method is routinely followed by the Geological Survey of India for the quantitative determination of $\mathrm{Ag}$ and $\mathrm{Cd}$ in soil and sediment samples collected under the NGCM program. The limit of quantitation $(10 \sigma)$ achieved for Cd was $2.0 \mathrm{ng} / \mathrm{g}$ and for $\mathrm{Ag} 5.0 \mathrm{ng} / \mathrm{g}$, with a recovery of $95-103 \%$.

\section{ACKNOWLEDGMENT}

The authors are highly grateful to the Director General, Geological Survey of India, for giving permission to publish this work. Thanks are also due to Dr. N.K. Roy, Retired Senior Deputy Director General (STSS), Geological Survey of India, for his keen suggestions and providing the facilities for this work.

Received January 29, 2015.

\section{REFERENCES}

1. K.H. Wedepohl, Geochem. et Cosmochem. Acta 59(7), 1217 (1995).

2. H.M. Kingston and S.J. Haswell (Eds.), Microwaves enhance chemistry. Fundamentals, sample preparation and applications, AES, Washington, DG, USA (1997).

3. John G. Viets, Richard M. O'Leary and J. Robert Clark, Analyst 109, 1589 (1984).

4. Zongshou Yu, Philip Robinson, and Peter McGoldrick, Geostd. Newsl. 25(2-3), 199 (2001).

5. M.C. Saha, T. Bhattacharya and N.K. Roy, Indian Minerals 59, 123 (2005).

6. Anindya Das and Manik C. Saha, At. Spectrosc. 34(2), 60 (2013).

7. J.G Sengupta and J.L Bouvier, Talanta 42(2), 269 (1995).

8. Zhongxi Li, Liping Zhou, and Feng Tan, Microchim. Acta 156, 263 (2007).
9. X. Xueijing, Analyst 120, 1497 (1995).

10. T. T. Chao and R. F. Sanzolone, J. Geochem. Expl. 44, 65 (1992).

11. V. Balaram, P.V.S. Raju, S.L. Ramesh, K.V. Anjaiah, B. Dasaram, C. Manikyamba, V.R. Mohan, and D.S. Sarma, At. Spectrosc. 20(4), 155 (1999).

12. John G. Viets, J. Geochem. Expl. 42, 107 (1992)

13. P.J. Potts, A Handbook of Silicate Rock Analysis, Blackie Academy and Professional, London, U.K., 187 (1987).

14. M.A. Rahman, S. Kaneco, and M. Amin, Talanta 62, 1047 (2004).

15. J.B. Borba da Silva, M.A. Mesquita da Silva, A.J. Curtius, and B.J. Welz, Anal. At. Spectrom. 14, 1737 (1999).

16. A. Vaisanen, R. Suontamo, J. Silvonen, and J. Rintala, Anal. Bioanal. Chem. 373, 93 (2002).

17. L.P. Zhou and Z. Li, Chin. J. Anal. Lab. 24(9), 20 (2005). 